\title{
Does long-term length of stay on board affect the repatriation rates of seafarers?
}

\author{
Antonio Roberto Abaya ${ }^{1}$, Jose Jaime Lorenzo De Rivera ${ }^{1}$, Saren Roldan ${ }^{1}$, Raymond Sarmiento ${ }^{2}$ \\ ${ }^{1}$ Health Metrics Inc., Makati, Philippines \\ ${ }^{2}$ National Telehealth Centre, National Institute of Health, University of the Philippines, Manila, Philippines
}

\begin{abstract}
Background: The length of seafarers' contract has undergone scrutiny regarding the health, welfare, and fatigue of the crew. This study investigates whether a stay of more than 200 days can increase the risk of medical repatriation among Filipino seafarers.

Materials and methods: We reviewed the number of medical repatriations from January 2014 to December 2016, specifically those who were repatriated after more than 200 days on board. We used WHO ICD-10 classification to categorise diseases and medical events that cause the repatriation, and classified them under "Injury" or "IIIness" as defined by the Occupational Injury and IIIness Classification Manual. We also separated those who worked on cargo vessels as well as those who worked on passenger ships. We requested for the total number of seafarers who worked longer than 200 days on board. After calculating a repatriation rate for this specific group of long-term workers, we then compared this with a previous study. Chi-square analysis and regression analysis were applied to analyse the data comparing the passenger versus cargo ships repatriation rates.

Results: There were a total of 840 cases of long-term repatriations in this study for the 3 year period. The total number of crew who had stayed for more than 200 days was 51,830. The different causes of repatriation are presented. Repatriation rates are also shown and a study of the regular stay and long term contracts are also compared.

Conclusions: There are various disease entities significantly higher in the long term work group. We offer some possible explanations for some of these differences in repatriation rates. This data could be useful in planning of schedules, work hours and contracts as well as the prevention of disease in seafarers.
\end{abstract}

(Int Marit Health 2018; 69, 3: 157-162)

Key words: maritime health, medical repatriation, seafarers

\section{INTRODUCTION}

Seafaring is widely considered a hazardous occupation [1], compounded by the fact that seafarers possess multiple risk factors particularly for lifestyle related diseases [2]. A survey in 1996 revealed that $62 \%$ of seafarers worked 8-12 hours per day, $11 \%$ worked $12-18$ hours, and $3 \%$ worked more than 18 hours [3]. These prolonged working hours are potential risk for fatigue at sea and can lead to hazardous impact on the shipping industry [4]. Fatigue in seafarers is regarded as a consequence of work stress, high job demands, insufficient crew members, long working hours, and disturbed circadian rhythms imposed by work- ing patterns and shift schedules, sleep deprivation and compromised safety standards [5]. The Maritime Labour Convention 2006 has taken into consideration fatigue and stress, mandating that the maximum seafarer's contract is 2 years of continuous work on board.

Despite this, seafarers comprise $90 \%$ of global commerce and are populated at about 1.6 million around the world [6]. Residing far from land inside the vessel, seafarers are susceptible to occupational hazards and emergency medical condition with limited access to medical care and treatment options. Therefore, screening protocol implementation from clinics which offer pre-employment and occupa- 
tional health interventions are enforced among seafarers to avoid medical repatriation while they are on board [7].

Repatriation is warranted when a ship owner is obligated to bring back crew members to their home country due to a severe defined condition under maritime regulations [8]. An example of which is when a seafarer is assessed to have a medical problem too severe to be treated on board. The seafarer is brought to a clinic or hospital with adequate medical facilities for the patient to have proper medical management. Unless the condition is an emergency, this initial management is usually only to stabilise the patient (i.e. symptomatically), whereupon they are sent home to complete treatment. The cost of repatriation falls on the ship owner, and includes transportation, lodging, and disability on top of the medical costs. This makes prevention of morbidities (and associated costs) highly valuable for research; indeed, there has been much scrutiny into the health of seafarers [8-10]. According to a study done by Abaya et al. (2015) [8] where medical repatriation cases in a 5-year period was investigated, the usual causes of medical repatriation among Filipino seafarers include injuries (trauma), musculoskeletal disorders, gastrointestinal problems, and genitourinary illnesses.

Given the multiple hazards and risks that seafarers are exposed to while on board, a longer the duration of a seafarer's stay would suggest a higher incidence of medical repatriation. Few articles have elaborated on this however. This study aims to determine whether a contract with a length over 200 days has a significant effect on repatriation rates. This may aid policy makers and other relevant agencies to formulate more specific occupational health policies and protocols in relation to the planning of schedules, duration of work hours, and length of contract of seafarers.

\section{MATERIALS AND METHODS}

The number of medical repatriations of crew members who have stayed more than 200 days on board from January 2014 to December 2016 was reviewed. This data was taken from records from Health Metrics Inc., a diagnostic clinic providing pre-embarkation medical exams to Filipino seafarers. Diseases and medical events that caused the repatriation were categorized using the WHO ICD-10 classification. Crew members were further categorised based on their vessel (i.e. cargo vs. passenger ships). Repatriation rates for these groups were then compared to known rates from previous studies, with $\chi^{2}$ analysis being used for the comparison. Data management and descriptive analyses were performed using Microsoft Excel.

\section{RESULTS}

A total of 51,830 crew members from the Philippines were reported to have stayed on board for more than 200 days from 2014 to 2016 on cargo and passenger ships. Among them, 840 crew members were repatriated due to medical concerns: 188 from cargo ships $(0.85 \%, 22,133$ cargo crew repatriations) and 652 from passenger ships (2.19\%, 29,697 passenger crew repatriations). In cargo ships, illnesses account for 796 (94.5\%) cases of repatriations, while injuries account for 69 (5.8\%) cases. Majority of illnesses comprise gastrointestinal and musculoskeletal complaints as shown below. In passenger ships, illnesses account for 139 (73.9\%) cases, while injuries account for 49 (26.1\%) cases (Fig. 1).

Among seafarers in the target population (> 200 days length of stay), the mean age for repatriation among passenger ship and cargo ship seafarers are 40.10 \pm 7.61 and $41.16 \pm 10.9$, respectively; overall mean age of repatriation is $40.34 \pm 8.46$. Among passenger ship seafarers, mean age for illness is not significantly different from mean age for injury (40.03 vs. 40.76, $p=0.472$ ). Similarly, among cargo ship seafarers, mean age for illness is not significantly different from mean age for injury (41.59 vs. 39.96, $p=0.273$ ). Overall, mean age for illness is not significantly different from mean age for injury (40.32 vs. 40.42, p=0.913).

Mean length of stay until repatriation are $246.12 \pm 49.9$ and $248.83 \pm 42.2$ days, respectively for passenger ship and cargo ship seafarers; overall mean length of stay until repatriation is $246.72 \pm 48.3$ days. As expected, there is no significant difference between the two means $(p=0.435)$. As seen in the diagram below, most of the length of stay data are clustered from 200 to 300 days, with the longest stay at 1,068 days (Fig. 2).

Detrimental outcomes (illness or injury) do not differ significantly across all ages $\left(X^{2}=59.455, p=0.073\right.$, df $\left.=45\right)$. These outcomes do not differ significantly across all ages, despite grouping the seafarers according to various age groups (15-24 - early working age; 25-54 - prime working age; 54 and above - mature working age and the elderly). This is interesting, since the frequency of illnesses and injury are highest in the prime working age group $(78.5 \%$ and $12.5 \%$, respectively) (Fig. 3).

Point-biserial correlation was run to determine the relationship between days of stay until repatriation and age at repatriation. There was no significant correlation found between the two variables $\left(r_{p b}=0.038, n=842, p=0.268\right)$.

\section{DISCUSSION}

There is an insufficient amount of studies regarding the effects of length of seafarers' stay on board with medical repatriation. Based on the study done previously [7], there also have not been other studies regarding causes of seafarer repatriations from the Philippines. This is important to have an insight on appropriate health interventions depending on the length of stay of seafarers, an understudied economic body of great importance. 


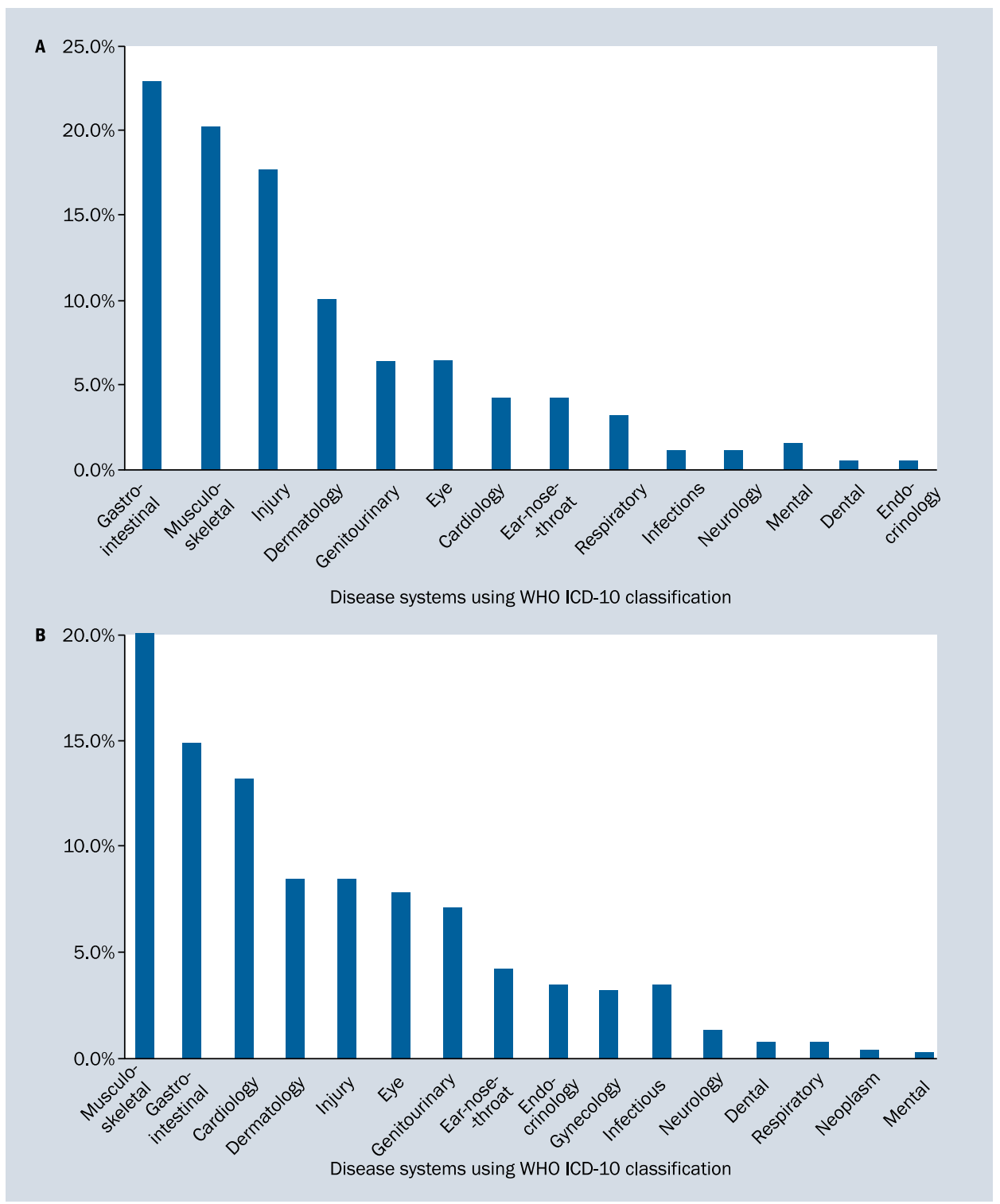

Figure 1. The graphs show the distribution of cases repatriated from cargo (A) and cruise (B) ships according to ICD-10 classification

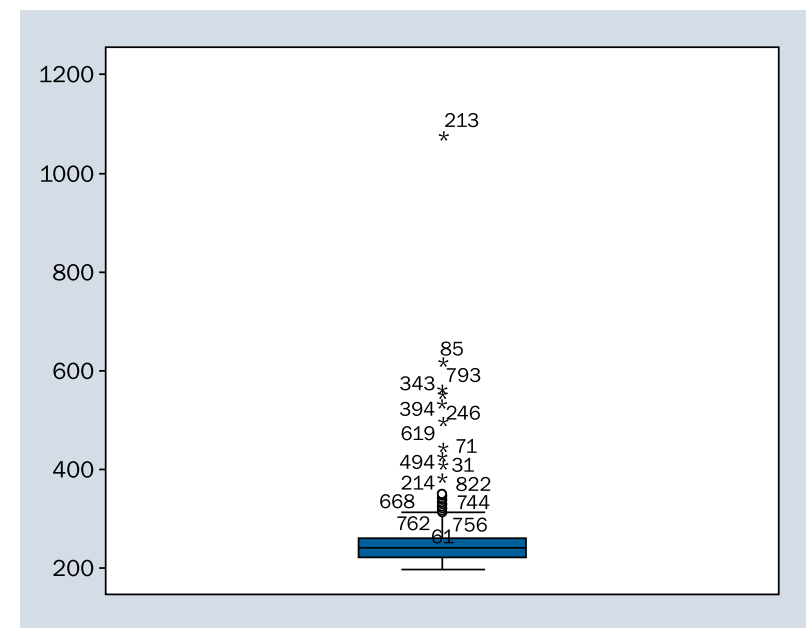

Figure 2. Histogram of length of stay for the subject population $(n=840)$
Crew members in cargo and passenger ships are subject to different working conditions and stressors. Cargo ships tend to have smaller crew sizes and involve more physically demanding work than do passenger ships [11]. This may explain the higher rate of repatriation due to injury in cargo ship crew. More social isolation (especially given long voyages) in cargo ships may also be linked to the higher number of psychiatric repatriations in these crew members $[11,12]$.

As we have noted in this 3-year study, medical repatriations are quite low, standing at $1.6 \%$ of the studied population. This is similar to medical repatriation rate of $1.7 \%$ observed in our previous study among Filipino seafarers (n $=388,963$ ) [8]. It must be noted that our studied population does not include seafarers repatriated within 200 days, and additional increases or decreases to our observed rate may be accounted for by the latter population. The low repatri- 


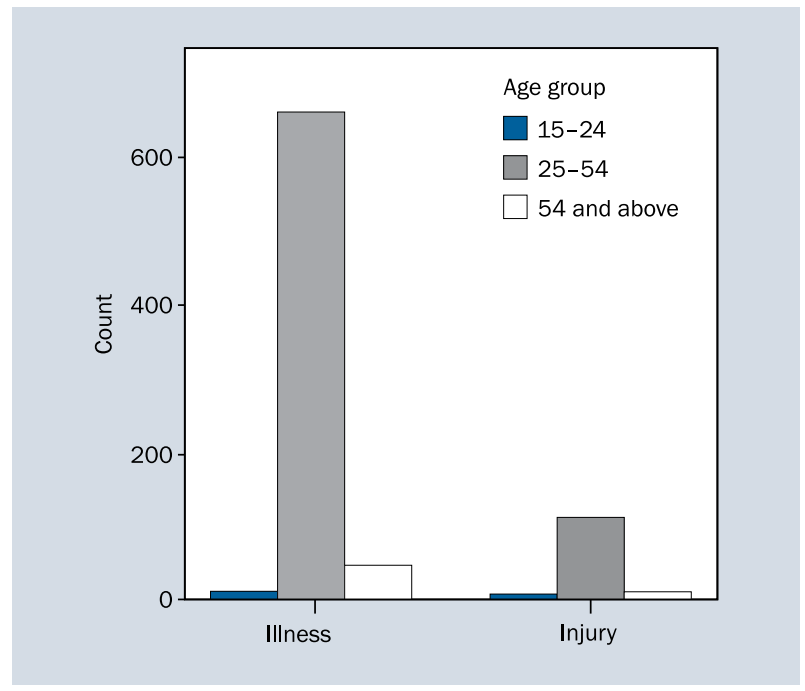

Figure 3. Total repatriation counts depending on age groups. Blue bars represent early working age 15-24, grey bars represent prime working age 25-54, white bars represent mature working age and elderly (54 and above)

ation rate can be attributed to the generally good health of Filipino Seafarers and the strict Pre-Employment Medical Examinations (PEMEs) done by accredited clinics, which make sure that all seafarers do not have health concerns before embarking the ships.

We found out that the mean length of stay of seafarers until repatriation is around 250 days, which is quite near the minimum contract length of 200 days imposed by most shipping companies. Most employers have a financial interest in health promotion and preventive programs, since repatriation costs are generally expensive [13]. As such, knowing that most repatriations happen within the first year aboard the ship, investment in such programmes would be a choice that would greatly benefit the employer and the seafarers themselves.

Contrastingly, we found out in our previous study [8] that injuries accounted for the highest numbers of repatriation causes (21.4\%). However, there is a strong case for arguing that there is a current paradigm shift from injury-related to medical-related repatriations, especially since in this study, we have found that illnesses comprise majority of repatriations after 200 days of deployment. Recent literatures have also cited illnesses to be more predominant than injuries, with rates up to twice as high $[8,14,15]$.

It was previously cited that main causes of work-related injuries, and subsequent injury-related repatriation, include insufficient awareness of safety, lack of use of personal protective devices, and inexperience [16]. The hypothesized decrease in injury-related repatriations might be brought about by recent improvements in occupational safety standards, as evidenced by continuous development of safety protocols [17] and reductions in mortality rates in uneventful disasters and accidents over the course of time [18]. With a minimum period of 200 days at sea, it would be prudent to presume that by then, seafarers are already familiar with safety protocol and experienced enough to handle required tasks. This would significantly decrease the number of work-related injuries and thus reduce injury-related repatriations. It is sensible, then, to confirm the earlier hypothesis through a future study characterising all repatriations from January 2014 to December 2016 regardless of length of stay and controlling them among age groups and ship job assignment.

Taking into consideration this decreasing trend of injury-related events, we hypothesize that injury count in our study might be an over-represented number. Predisposing illnesses deemed by seafarers to be too minor to be reported to the medical staff are most likely to be the root cause of injuries. In such a stressful occupation such as seafaring, risk factors for work-related musculoskeletal diseases abound, such as physical load (hand force exertion, repetitive movements, work posture), work environment (poor workspace layout, temperature, lighting, noise levels, vibration), organisational factors (working under pressure, high work of demands, poor job design, etc.), and individual factors (gender, age). Naturally, the risk of injury increases since majority, if not all, risk factors are combined [19]. Additionally, it was reported that disability was more often secondary to illness [14]. For instance, a seafarer assigned on deck having a persistent but manageable musculoskeletal illness (e.g., unspecified musculoskeletal pain across different body parts) might continue his work, only to end up having an injury due to culminating weakness at that unfortunate time. Similar scenarios might be played out, and would be most likely elicited from medical history; however, the study is only limited to analysing final diagnoses that prompt repatriation and not extensive chart-reviewing.

In the study, it was found out that the frequency of illnesses and injuries do not significantly differ across the three age groups. This implies that all age groups are predisposed to developing illnesses and having injuries that will cause repatriation. Therefore, it is fitting that PEMEs be done thoroughly in order to identify any conditions and risk factors and provide early intervention for seafarers. This distribution of illnesses and injuries among all age groups also reinforces that medical examinations should be performed every 2 years, as recommended by the International Labour Organisation, to monitor seafarers' fitness for work; this can be done at shorter intervals in response to a health condition that requires more frequent surveillance [20]. Recently, there also has been interest in identifying medical tests that may help in monitoring the conditions of seafarers. Relatedly, a recent study identified nine blood 
chemistry measures that can provide monitoring of the effect of long-distance voyage on seamen's health, including monoamine oxidase, creatine kinase, and serum albumin [21]; however, further research must be done to confirm any value on these blood chemistry measures.

We tried to determine whether age at repatriation correlates with length of stay until repatriation. Age is an important measure of experience and physical fitness. Younger seafarers are viewed as inexperienced yet more physically fit, while older seafarers are seen as the converse; as such, early repatriations may be attributed to the young and the old. Due to constraints of analysing over 51,000 cases, we opted to use a point-biserial correlation analysis in our smaller population for the purposes of this research. The analysis does not reveal any significant relationship between the two. However, despite our research providing an initial clue regarding this aspect, future studies may opt to use multinomial regression analysis targeted at both non-repatriated and repatriated seafarers. This will better predict the length of stay until repatriation using age, presence/ /absence of any illnesses or injuries, and type of illness/ /injury as variables. Pre-determined knowledge, attitudes, and practices of seafarers can also be taken into account and inserted as well into the analysis.

Moreover, it is noted that our reported values have large standard deviations; this is due to outliers present in the given data. A larger sample size must be used in future researches to minimise the skewness of the data to be analysed.

\section{CONCLUSIONS}

In this study, we determined a repatriation rate of $1.6 \%$ among cargo ship and passenger ship seafarers who have stayed for more than 200 days at sea, with illnesses as the major cause for both populations $(94.5 \%$ and $73.9 \%$ for cargo and passenger ship seafarers, respectively). Mean length of stay until repatriation is $246.72 \pm 48.3$ days, while mean age at repatriation is $40.34 \pm 8.46$. There appears to be no correlation between length of stay and age at repatriation. Distribution of illnesses and injuries appear to be not significantly different across all age groups examined. It appears that repatriation due to medical causes has no predilection towards certain subpopulations. Therefore, it is prudent for shipping companies to invest in strict pre-employment medical examinations, proper health interventions, and reinforced preventive measures to avoid future repatriations and associated costs. Future researches must focus on obtaining larger sample sizes, as well as including data from non-repatriated and non-medically-repatriated seafarers to further build a better prognostic model for identifying relationships between presence and type of illnesses/injuries, age, and length of stay until repatriation.

\section{REFERENCES}

1. US Department of Labor. (1992). Occupational Injury and Illness Classification Manual. https://www.bls.gov/iif/oshwc/ oiicm.pdf.

2. Iversen RTB. The mental health of seafarers. Int Marit Health. 2012; 63(2): 78-89, indexed in Pubmed: 22972547.

3. Alderton T, Bloor M. Seafarers International Research Centre, International Labour Office, E. Kahveci, T. Lane, H. Sampson, M. Zhao, M. Thomas, Nik Winchester, Bin Wu The Global Seafarer: Living and Working Conditions in a Globalized Industry.

4. Huanxin. Wang (2012) Study on the assessment of seafarers' fatigue. World Maritime University The Maritime Commons: Digital Repository of the World Maritime University.

5. Slišković A, Penezić Z. Occupational stressors, risks and health in the seafaring population. Review of Psychology. 2016; 22(12): 29-39, doi: 10.21465/rp0022.0004.

6. Baygi F, Jensen OC, Mohammadi-Nasrabadi F, et al. Factors affecting health-promoting lifestyle profile in Iranian male seafarers working on tankers. Int Marit Health. 2017; 68(1): 1-6, doi: 10.5603/IMH.2017.0001, indexed in Pubmed: 28357829.

7. Lefkowitz RY, Slade MD, Redlich CA. Injury, illness, and disability risk in American seafarers. Am J Ind Med. 2018; 61(2): 120-129, doi: 10.1002/ajim.22802, indexed in Pubmed: 29250811.

8. Abaya AR, Roldan S, Ongchangco JC, et al. Repatriation rates in Filipino seafarers: a five-year study of 6,759 cases. Int Marit Health. 2015; 66(4): 189-195, doi: 10.5603/IMH.2015.0038, indexed in Pubmed: 26726888.

9. Lefkowitz RY, Slade MD, Redlich CA. Risk factors for merchant seafarer repatriation due to injury or illness at sea. Int Marit Health. 2015; 66(2): 61-66, doi: 10.5603/IMH.2015.0016, indexed in Pubmed: 26119673.

10. Bell SSJ, Jensen OC. An analysis of the diagnoses resulting in repatriation of seafarers of different nationalities working on board passenger ships, to inform pre-embarkation medical examination. Medicina Maritima. 2009; 9(1): 32-43.

11. Carter T. Mapping the knowledge base for maritime health: 3 illness and injury in seafarers. Int Marit Health. 2011; 62(4): 224-240, indexed in Pubmed: 22544497.

12. Oldenburg $M$, Jensen HJ, Latza U, et al. Seafaring stressors aboard merchant and passenger ships. Int J Public Health. 2009; 54(2): 96-105, doi: 10.1007/s00038-009-7067-z, indexed in Pubmed: 19288290.

13. Faurby MD, Jensen OC, Hjarnoe L, et al. The costs of repatriating an ill seafarer: a micro-costing approach. Health Econ Rev. 2017; 7(1): 46, doi: 10.1186/s13561-017-0184-0, indexed in Pubmed: 29209881.

14. Lefkowitz RY, Slade MD, Redlich CA. Am J Ind Med. 2015; 58(6): 688-696, doi: 10.1002/ajim.22459, indexed in Pubmed: 25939921.

15. Jensen OC, Laursen FV, Sorensen FL. International surveillance of seafarers' health and working environment. A pilot study of the method. Preliminary report. Int Marit Health. 2001; 52(1-4): 59-67.

16. Oldenburg M, Baur X, Schlaich C. Occupational risks and challenges of seafaring. J Occup Health. 2010; 52(5): 249-256, indexed in Pubmed: 20661002.

17. International Labor Organization. (2014). New safety and health guidelines to protect seafarers. http://www.ilo.org/ global/about-the-ilo/newsroom/news/WCMS_315405/lang-en/index.htm. 
18. Roberts SE. Fatal work-related accidents in UK merchant shipping from 1919 to 2005. Occup Med (Lond). 2008; 58(2): 129-137, doi: $10.1093 /$ occmed/kqm149, indexed in Pubmed: 18156636.

19. Petreanu V, Seracin A (2017). Risk factors for musculoskeletal disorders development: hand-arm tasks, repetitive work. https://oshwiki.eu/wiki/Risk_factors_for_musculoskeletal_disorders_development:_hand-arm_tasks,_repetitive_work\# Risk_factors_for_work-related_neck_and_upper_limb_disorders.
20. International Labor Organization. (2013). Guidelines on the medical examinations of seafarers. http://www.ilo.org/wcmsp5/ groups/public/_ed_dialogue/-sector/documents/normativeinstrument/wcms_174794.pdf (2013).

21. Lu Y, Gao Y, Cao Z, et al. A study of health effects of long-distance ocean voyages on seamen using a data classification approach. BMC Med Inform Decis Mak. 2010; 10: 13, doi: 10.1186/14726947-10-13, indexed in Pubmed: 20219089. 